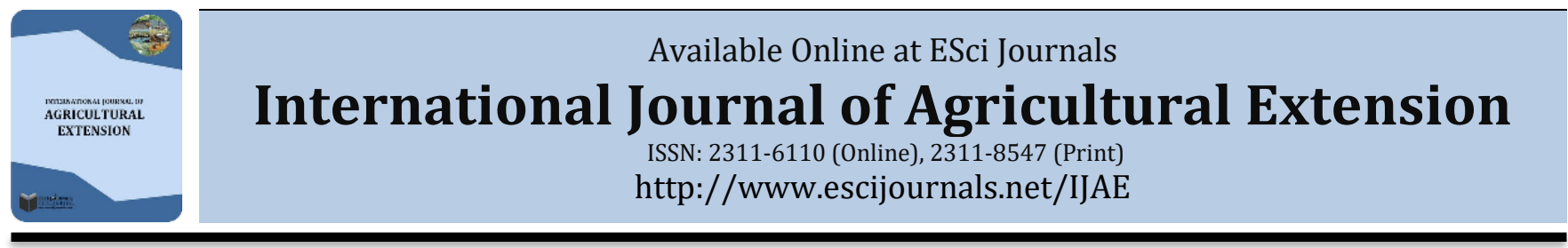

\title{
IDENTIFICATION AND PRIORITIZATION OF AGRICULTURAL RISKS WITH SPECIAL CONTEXT OF RICE CROP IN THE PUNJAB, PAKISTAN
}

\author{
Muhammad Iftikhar*, Ghazanfar Ali Khan, Jawad Hussain \\ Institute of Agricultural Extension and Rural Development, University of Agriculture Faisalabad, Pakistan.
}

\section{A B S T R A C T}

This study was conducted to explore the production and marketing risks as perceived by the rice growers. The study was conducted in District Sheikhupura of Punjab province. The study area is fully conducive for rice cultivation. Of the rice-growing farmers, 100 were purposively selected to interview. Data were collected through interview Schedule and analyzed with the Statistical Package for Social Sciences (SPSS). The results depicted that the prominent risks appeared "high prices of inputs", "price conflict between farmers, labour and buyer", "fluctuations in the prices of inputs" and "high/low rainfall". While the prominent coping strategy emerged as "information sharing with the community". In this context, there should be some sound policies for price control of inputs. Moreover, the conflicts among the farmers, labour and buyer should be reduced by opting the conflict resolution strategy according to the situation. There is a need for effective and strengthened information sharing system for farmers.

Keywords: Farming risks, production risks, rice crop, rice zone, marketing risks, harvesting risks.

\section{INTRODUCTION}

Pakistan is an agricultural country. Agriculture sector contributed $18.9 \%$ to Gross Domestic Product (GDP) of country. Agriculture sector is the sole source of livelihood for peoples living in isolated and sparsely areas (peoples living in villages) and it accounts as an income source for 42.3 percent population living in rural areas of Pakistan (GOP, 2019). Agriculture is Pakistan is assumed complex with varied on farm results. However, in last decade agriculture sector is turning to be more complex and farmers are found poorly interested to pursue farming as profession. To meet food requirements of the increasing population adopting agriculture as a profitable business and profession is inevitable in Pakistan. The only possible solution to feed increasing mouths in the country is doubling production of major staple crops like wheat and rice.

Agriculture is considerably a risky business and entailing risks could be the possibly factors behind lowering interests of farmers in farming. For instance, In Pakistan with the passage of time dependents on

* Corresponding Author:

Email: muhammad.iftikhar@uaf.edu.pk

(C) 2019 ESci Journals Publishing. All rights reserved. farming are decreasing. Currently $42.3 \%$ people are reliant on farming (GOP, 2018). Agricultural risks may vary in their kinds, i.e. marketing risks originating because of non-availability of well-established marketing system and catastrophic risks which are results of environmental abnormalities (Hardaker et al., 2004). In farming business risk can not only originate from insect pest, seed or fertilizer adulteration, climatic issue i.e. high or low temperature, high or low rainfall, and floods (Coble et al., 2008). Production risks are an aggregation of a number of factors such as climatic sensitivities and human-associated factors such as late sowing. Production risk includes uncontrollable events that are unfortunate and are most of the time not in control of human being. All the factors like high/low temperature, drought, flood, high or low rainfall, and insect or disease outbreak categorize as production risks because these risks occur during the production phase of the crop, so they kept in the category of production risk (Ashraf et al., 2013; Rider et al., 2015). Fluctuation in input prices and unavailability of inputs or availability of the poor quality of inputs can result in lowering the expected output which can be an associated source of increasing marked risks in agriculture (Wassmann et al., 
2009). Shortage of certified seed, non-availability of fertilizers at the time of peak season, adulteration of fertilizers, Insect-pest/disease outbreak, Irrigation water shortage, adulteration of weedicides, use of inappropriate spraying techniques, fuel prices (Diesel +Electricity prices), black marketing of inputs are some kinds of input risks (Jaffee et al., 2010).

Rice is one of the most important crops in Pakistan after wheat. Rice was cultivated on an area of 2899 thousand hectares in 2017 with a total production of 7 thousand tonnes (GOP, 2019). This production is higher than the previous year when production faced an acute decline subject to reduction in cultivated area and less economic returns to farmers. In addition, poor export of basmati rice led restricted farmers to cultivated rice crop (GOP, 2016). The average yield of rice crop obtained is 2,567 $\mathrm{kg} /$ hectare which is considerably lower than the potential (GOP, 2019). This under potential production is attributed to several factors termed as agricultural risks. To integrate appropriate measures identification and prioritization of persisting risks is obligatory. Until this year, there is no significant study in the Punjab province in particular identifying the risks as perceived by the rice growers. Therefore, this study is distinctive in nature to address different risks as perceived by the rice growers.

\section{METHODOLOGY}

Punjab province of Pakistan is dominant in agriculture sector being blessed with all natural resources required for the profitable farming. Provinces comprises of thirty six districts and a plethora of crops are cultivated in different districts. After, cotton, wheat, sugarcane, Rice has a distinguished position and importance for the livelihoods of farmers, economy of country and consumers to meet their dietary needs. Of the total districts, Sheikhupura is one of the key region famous around the world for its aromatic rice production.

Sheikhupura district lies in the rice cropping zone of Punjab, Pakistan. Therefore, sheikhupura was selected as study area. The rice growers of District Sheikhupura served as the population for the present study. District Sheikhupura further sub-divided into 5 tehsils (subdistricts) named as Sheikhupura, Ferozwala, Muridky, Sharqpur and Safdarabad. All tehsils were favourable to rice cultivation thus it was planned to select respondents from all tehsils.

From each tehsil, two villages were selected purposively. From each selected village 10 farmers (rice growers) were selected purposively, thereby making a sample size of 100 rice growers.

In order to collect the required information, an interview schedule was developed keeping in view the objectives of the study. This interview schedule was structured, validated and reliable. Prior final data collection interview schedule was pre-tested on 20 rice farmers. These farmers were other than the selected respondents. On basis of pre-testing results minor changes were made the interview schedule.

Collected data was coded into excel sheet and then exported to computer software Statistical Package for Social Sciences (SPSS) sheet for analysis. Descriptive statistics such as frequency, percentage, mean and standard deviation (SD) was applied to data for meaningful interpretation.

\section{RESULTS AND DISCUSSION}

Table1. Distribution of respondents according to their demographic characteristics.

\begin{tabular}{|c|c|c|}
\hline Demographic attributes & Frequency & $\%$ \\
\hline \multicolumn{3}{|c|}{ Age } \\
\hline$\leq 35$ years & 38 & 38 \\
\hline $36-50$ & 33 & 33 \\
\hline$\geq 50$ years & 29 & 29 \\
\hline \multicolumn{3}{|c|}{ Education } \\
\hline Illiterate & 40 & 40 \\
\hline Literate & 60 & 60 \\
\hline \multicolumn{3}{|c|}{ Land holding size } \\
\hline$>12.5$ acers & 55 & 55 \\
\hline$<12.5-25$ acers & 20 & 20 \\
\hline$<25$ acers & 25 & 25 \\
\hline
\end{tabular}




\begin{tabular}{|c|c|c|}
\hline \multicolumn{3}{|c|}{ Tenancy status } \\
\hline Owner & 53 & 53 \\
\hline Tenant & 23 & 23 \\
\hline Owner-cum-Tenant & 24 & 24 \\
\hline \multicolumn{3}{|c|}{ Area under rice cultivation } \\
\hline$>12.5$ & 66 & 66 \\
\hline$<12.5-25$ & 17 & 17 \\
\hline$<25$ Acres & 17 & 17 \\
\hline
\end{tabular}

Demographic attributes of the respondents: Table 1 depicts that $38 \%$ respondents fell into the age bracket of less than 35 years age followed by almost one-third respondent (33\%) felling into the age bracket of 36-50 years. Of the total respondents, $29 \%$ were considerably older surpassing 50 years of age. Findings of Hussain (2017) are in support of this study as respondents in the age bracket of less than 35 years were reported prominent.

Table 1 further reflects that $60 \%$ respondents were literate and $40 \%$ were illiterate. More than half (55\%) respondents had a land holding of less than 12.5 acres. One fifth $(20 \%)$ respondents had landholding from 12.5 to 25 acres. One fourth (25\%) respondents had large size of land (more than 25 acres). Ahmad et al, (2002) and Khan et al, (2011) had reported the same results that most of the farmers in the study area were small farmers. Apart from being small farmers, more than half of the respondents (53\%) were found owners of their lands in this study followed by $23 \%$ tenants and $24 \%$ owner-cum-tenants.

Farmers practising rice on small land holdings (less than 12.5 acres) were prominent while $17 \%$ had rice cultivation on $12.5-25$ and more than 25 acres respectively.

Production risks: Production risks include risks that happen during the production cycle of crops. Production risks include high/ low rainfall, high/low temperature, drought, flood and late sowing (Turvey, 2001). Keeping in view the research objective, the respondents were asked to report perceived production risks on five point Likert scale.

Table 2. Different production risks faced by respondents.

\begin{tabular}{lcc}
\hline Production risks & Mean & SD \\
\hline High/Low Rainfall & 2.43 & 1.13 \\
High Temperature & 1.94 & 1.17 \\
Late sowing & 1.17 & 1.16 \\
\hline
\end{tabular}

The data in Table 2 show that respondents were considering high/low rainfall as a major production risk. The extent of high/low rainfall (mean value, 2.43) falls between low and medium level. The mean value of high temperature means value (1.94) falls between very low to a low extent but tended much more towards low level. At the least cadre was late sowing mean value (1.17) falling between very low to low but more inclined towards a very low extent.

The above results are in line with Heckelei et al. (2012), who concluded that weather uncertainties such as high temperature and rainfall were among top facing risks by rice growers. Results of the present study also express similar indicators as that of Mosnier et al. (2009), where they also suggest that in production cycle high low rainfall and temperature are harsh reasons for low production and these are an expression of climate change throughout the world.

Input risks: Arndt et al. (2015) stated that the high value of input costs, scarcity of economic resources, lack of access to the main cotton markets and skilful and experienced farmers to utilize the input with proper management, ultimately reduce the yield and chart eristic of cotton that impact on farmer benefits. The use of inputs has a direct bearing on the production and profit of the fanners. He found that cultivation labour cost, sowing cost, seed, fertilizer, pesticide, irrigation and labour are the important variables in the production of cotton. Plant protection and irrigation are the most important factors which affect the cost of production. Different input risks have to face by respondents in the study area such as shortage of certified seed, 
adulteration of fertilizer, high cost of input etc. so they were asked about to which extent they are facing input risks.

Data in Table 3 present that high price of input was considered as the first ranked input risk faced by respondents, having a mean value of 3.52 which lies between medium and high. The high cost of mechanization was considered as second-ranked risk faced by respondents, having a mean value of 3.37 lies between medium and high but tended more towards the medium. Fuel prize was considered as third-ranked risk having a mean value of 2.96 which lies between low and medium but seems almost medium. Insect pest outbreak was ranked on fourth position having a mean value of 2.46 lies between low and medium. Shortage of certified seed was ranked in fifth position having mean value (2.37) lies between low and medium. Similarly, adulteration of weedicide (mean 2.31), black market (mean 2.25), and use of inappropriate spraying technique (2.17) appeared on the scene. While nonavailability of fertilizer with mean value 2.03 shows low extent. Irrigation water shortage was at the lowest position having mean value (1.96) lies at the position of near low extent.

Table 3. Input risks faced by respondents.

\begin{tabular}{lcc}
\hline Input Risk & Mean & SD \\
\hline The high price of inputs & 3.52 & 1.01 \\
High cost of mechanization & 3.37 & 1.14 \\
Fuel price & 2.96 & 1.23 \\
Insect pest Outbreak & 2.46 & 1.26 \\
Shortage of certified seed & 2.37 & 1.66 \\
Adulteration of weedicide & 2.31 & 1.24 \\
Black marketing of inputs & 2.25 & 1.56 \\
Adulteration of fertilizer & 2.24 & 1.26 \\
Use of inappropriate spraying technique & 2.17 & 1.28 \\
Non-availability of fertilizer at the time of peak season & 2.03 & 1.45 \\
Irrigation water shortage & 1.97 & 1.7 \\
\hline
\end{tabular}

Harvesting risks: Risks that occur after maturation of crops categorized as harvesting risks. After maturation of crop uncertainties such as unavailability of labour, unavailability of transport poor marketing infrastructure etc. may happens which can bring a valuable downfall in profit graph. Despite good outcomes most of the times no availability of labour, more moisture in the air, shrinking and shedding of grain due to loss of moisturizing contents quality of product decline. Different type of harvesting risks such as having no or less availability of storing or handling techniques, having no or less availability of storing or handling techniques, less availability of labour at the time of harvesting, price conflict between labour, buyer and farmer.

Table 4. Different harvesting risks faced by respondents.

\begin{tabular}{lll}
\hline Harvesting Risks & Mean & SD \\
\hline Price conflict between labour buyer and farmer & 3.04 & 1.19 \\
Less availability of labour & 2.44 & 1.64 \\
Non-availability of mechanical harvesting & 2.19 & 1.30 \\
The high cost of labouring & 2.10 & 1.30 \\
Inappropriate handling/ storing & 2.03 & 1.41 \\
Contamination during harvesting & 1.98 & 1.30 \\
No or less availability of skilled labour & 1.63 & 1.53 \\
\hline
\end{tabular}

Data in Table 4 depict that price conflict between farmers, labour and buyer was first harvesting risk faced by respondents, having a mean value of 3.04 indicating the medium extent. Less Availability of labour was 
considered as second top-facing harvesting risk, having a mean value of 2.44 lies between low and medium. Nonavailability of mechanical harvesting was considered as third most facing harvesting risk by respondents, having a mean value of 2.19 lies between low and medium but more inclined towards a low extent. Other risks such as high cost of labouring, inappropriate handling/ storing, contamination during harvesting, no or less availability of skilled labour were other facing harvesting risks categorized on 4th, 5th, 6th and 7th position, having a mean value of 2.10, 2.03,1.98, 1.63 respectively.

Marketing risks: After a good production ultimate reward of a farmer goes into the market. A market is a place where sellers and buyers interact with each other and communicate. In the market is highly unpredictable. Middle man monopoly and poor legal interference farmers have to bear losses despite having good production. Data in this regard is mentioned in Table 5.

Table 5. Different marketing risks faced by respondents.

\begin{tabular}{lcc}
\hline Market Risk & Mean & SD \\
\hline Fluctuations in the prices of inputs like fertilizer/seed/pesticides etc. & 3.27 & 0.93 \\
Middleman monopoly & 3.01 & 1.10 \\
Changes in market demands for the timing of product delivery & 2.93 & 1.16 \\
Fluctuations in market rates of agricultural products & 2.92 & 1.00 \\
Buyers monopoly & 2.92 & 1.24 \\
Money Inflation & 2.69 & 1.36 \\
Inadequate information about the market & 2.60 & 1.21 \\
The high interest rate on the loan & 2.33 & 1.44 \\
WTO quality standards & 1.83 & 1.63 \\
Substandard market roads in peripheral & 1.67 & 1.60 \\
\hline
\end{tabular}

Data presented in Table 5 indicate that "Fluctuations in the prices of inputs" appeared as relatively conspicuous marketing risk with mean value (3.27) lies between medium to a high extent but more inclined towards a medium extent. The subsequent prominent risk indicated by the respondents was "middleman monopoly" with mean value (3.01) indicating medium extent. Changes in market demands, fluctuations in market rates of agricultural products, and buyers' monopoly emerged risks with mean values 2.93, 2.92, 2.92 respectively.
Other subsequent risks identified were money inflation and inadequate information about the market with means values (2.69 and 2.60) lies between low and medium but tended towards the medium. At the lower cadre, there were risks "WTO quality standards" and "substandard market roads in peripheral" with means values (1.83 and 1.67) between very low towards low extent but more inclined to low. From the results, it obvious that the indicated prominent marketing risks were "changes in market demands" and middleman monopoly."

Table 6. Strategies being adopted by the growers to cope with the impact of the existing risk.

\begin{tabular}{lcc}
\hline Risk Management Strategies & Mean & SD \\
\hline Information sharing within the community & 2.81 & 1.33 \\
Selling financial assets & 2.35 & 1.46 \\
Borrowing from neighbours & 2.31 & 1.23 \\
Livestock rearing & 2.30 & 1.69 \\
Adoption of prevention measures to control diseases & 2.03 & 1.29 \\
Off -farm employment & 1.50 & 1.38 \\
Loaning from banks & 1.24 & 1.46 \\
\hline
\end{tabular}

Data in Table 6 show that information sharing with the community was first ranked strategy being adopted by farmers in the study area to minimize the existing risks having a mean value of 2.81 lies between the low and 
medium but more inclined towards the medium. Selling of financial assets was ranked on second position having a mean value of 2.35. Burrowing from neighbours was ranked on third position having a mean value of 2.31 . Livestock rearing was ranked on the fourth position as coping strategy having a mean value of 2.30. Aforesaid mean values $(2.35,2.31$ and 2.30$)$ lies between the low and high but inclined towards a low extent. Adoption of preventive measures to control disease was ranked in fifth position having a mean value of 2.03 showing low extent. Off farm, employment was ranked on the sixth position with a mean value of 1.50 lies between very low to low extents. Loaning from banks was ranked on the seventh position having a mean value of 1.24 lies between very low to low but tended towards very low.

\section{CONCLUSIONS AND RECOMMENDATIONS}

The prominent risks appeared "high prices of inputs", "price conflict between farmers, labour and buyer", "fluctuations in the prices of inputs" and "high/low rainfall". While the prominent coping strategy emerged as "information sharing with the community". In this context, there should be some sound policies for price control of inputs. Moreover, the conflicts among the farmers, labour and buyer should be reduced by opting the conflict resolution strategy according to the situation. The information sharing system should be enhanced and strengthened.

\section{ACKNOWLEDGEMENT}

The research paper is a part of the Higher Education Commission (HEC), Islamabad funded project entitled "Policy devising study of agricultural risks and their management in different cropping zones of Punjab, Pakistan". The financial assistance of HEC for the said project is highly appreciated and acknowledged.

\section{REFERENCES}

Ahmad, M., G. M. Chaudhry \& M. Iqbal. (2002). Wheat Productivity, Efficiency, and Sustainability: A Stochastic Production Frontier Analysis, The Pakistan Development Review, 41(4), 643- 66.

Arndt, C., Pauw, K. and Thurlow, J. (2015). The economywide impacts and risks of Malawi's farm input subsidy program. American Journal of Agricultural Economics, 98(3), 962-980.

Ashraf, S., M. Iftikhar, G.A. Khan. (2013). Decisive analysis of risks in agriculture: implications for agricultural extension for sustainable management, Spanish Journal of Rural Development, 4(3), 41-52, 2013
Coble, K. H., \& Barnett, B. J. (2008). An assessment of risk exposure in agriculture: A literature review. Organisation for Economic Co-Operation and Development (OECD), Paris.

GOP. 2016. Economic Survey of Pakistan (2015-16). Ministry of Finance Govt. of Pakistan [Online] www.finance.gov.pk/survey/chapters_16/Overvie w_of_the_Economy.

Hardaker, J.B., Richardson, J.W.G., Lien, D. (2004). Stochastic efficiency analysis with risk aversion bounds: a simplified approach. Australian Journal of Agricultural in Resource Economics 48, 253270

Heckelei, T., Britz, W., \& Zhang, Y. (2012). Positive mathematical programming approaches - recent developments in literature and applied modelling. Bio-Based and Applied Economics, 1(1), 109-124.

Hussain, J. 2017. Farmers' and industrial perception regarding adoption of sisal as new fiber crop in Punjab Pakistan. M.Sc. (Hons.) Thesis, Deptt. Of Agri. Ext. Univ. of Agri., Faisalabad.

Jaffee, S., Siegel, P., \& Andrews, C. (2010). Rapid agricultural supply chain risk assessment: A conceptual framework. Agriculture and rural development discussion paper, 47(1), 1-64.

Khan, B. M., I. S. Chaudhry \& M. H. Akhtar. (2011). Cost benefit analysis of cotton production and processing by stakeholders: The case study of Multan and Bahawapur region. American J. of Sci Res. 13, 131-141.

Mosnier, C., Agabriel, J., Lherm, M., \& Reynaud, A. (2009). A dynamic bio-economic model to simulate optimal adjustments of suckler cow farm management to production and market shocks in France. Agricultural Systems, 102(3), 77-88.

Muthayya, S., Sugimoto, J. D., Montgomery, S., \& Maberly, G. F. (2014). An overview of global rice production, supply, trade, and consumption. Annals of the new york Academy of Sciences, 1324(1), 7-14.

Ridier, A., Chaib, K., \& Roussy, C. (2016). A Dynamic Stochastic Programming model of crop rotation choice to test the adoption of long rotation under price and production risks. European Journal of Operational Research, 252(1), 270-279.

Turvey, C. G. (2001). Weather derivatives for specific event risks in agriculture. Review of Agricultural Economics, 23(2), 333-351. 
Wassmann, R., Jagadish, S. V. K., Heuer, S., Ismail, A., Redona, E., Serraj, R. \& Sumfleth, K. (2009). Climate change affecting rice production: the physiological and agronomic basis for possible adaptation strategies. Advances in agronomy, 101, 59-122.

(ब) (1) 